\title{
Polar Middle Atmospheric Responses to Medium Energy Electron (MEE) Precipitation Using Numerical Model Simulations
}

\author{
Ji-Hee Lee ${ }^{1}$, Geonhwa Jee ${ }^{1,2, *(\mathbb{D}) \text {, Young-Sil Kwak }}{ }^{3,4}{ }^{\text {, Heejin Hwang }}{ }^{1}$, Annika Seppälä ${ }^{5}$, In-Sun Song ${ }^{1}$, \\ Esa Turunen ${ }^{6}$ and Dae-Young Lee ${ }^{7}$ \\ 1 Korea Polar Research Institute, Incheon 21990, Korea; leejihee@kopri.re.kr (J.-H.L.); heejin@kopri.re.kr (H.H.); \\ isong@kopri.re.kr (I.-S.S.) \\ 2 Department of Polar Science, Korea University of Science and Technology, Incheon 21990, Korea \\ 3 Space Science Division, Korea Astronomy and Space Science Institute, Daejeon 34055, Korea; \\ yskwak@kasi.re.kr \\ 4 Department of Astronomy and Space Science, Korea University of Science and Technology, \\ Incheon 21990, Korea \\ 5 Department of Physics, University of Otago, Dunedin 9016, New Zealand; annika.seppala@otago.ac.nz \\ 6 Sodankylä Geophysical Observatory, University of Oulu, 99600 Tähteläntie, Finland; et@sgo.fi \\ 7 Department of Astronomy and Space Science, Chungbuk National University, Cheongju 28644, Korea; \\ dylee@chungbuk.ac.kr \\ * Correspondence: ghjee@kopri.re.kr
}

check for updates

Citation: Lee, J.-H.; Jee, G.;

Kwak, Y.-S.; Hwang, H.; Seppälä, A.;

Song, I.-S.; Turunen, E.; Lee, D.-Y.

Polar Middle Atmospheric Responses

to Medium Energy Electron (MEE)

Precipitation Using Numerical Model

Simulations. Atmosphere 2021, 12, 133.

https: / / doi.org/10.3390/

atmos12020133

Received: 9 December 2020

Accepted: 15 January 2021

Published: 20 January 2021

Publisher's Note: MDPI stays neutral with regard to jurisdictional claims in published maps and institutional affiliations.

Copyright: (c) 2021 by the authors. Licensee MDPI, Basel, Switzerland. This article is an open access article distributed under the terms and conditions of the Creative Commons Attribution (CC BY) license (https:// creativecommons.org/licenses/by/ $4.0 /)$.

\begin{abstract}
Energetic particle precipitation (EPP) is known to be an important source of chemical changes in the polar middle atmosphere in winter. Recent modeling studies further suggest that chemical changes induced by EPP can also cause dynamic changes in the middle atmosphere. In this study, we investigated the atmospheric responses to the precipitation of medium-to-high energy electrons (MEEs) over the period 2005-2013 using the Specific Dynamics Whole Atmosphere Community Climate Model (SD-WACCM). Our results show that the MEE precipitation significantly increases the amounts of $\mathrm{NO}_{\mathrm{x}}$ and $\mathrm{HO}_{\mathrm{x}}$, resulting in mesospheric and stratospheric ozone losses by up to $60 \%$ and $25 \%$ respectively during polar winter. The MEE-induced ozone loss generally increases the temperature in the lower mesosphere but decreases the temperature in the upper mesosphere with large year-to-year variability, not only by radiative effects but also by adiabatic effects. The adiabatic effects by meridional circulation changes may be dominant for the mesospheric temperature changes. In particular, the meridional circulation changes occasionally act in opposite ways to vary the temperature in terms of height variations, especially at around the solar minimum period with low geomagnetic activity, which cancels out the temperature changes to make the average small in the polar mesosphere for the 9-year period.
\end{abstract}

Keywords: medium energy electron (MEE); energetic electron precipitation (EEP); mesosphere; odd-nitrogen; odd-hydrogen; ozone loss

\section{Introduction}

The variation of the solar irradiance with solar activity has been considered to be one of the major natural forcings influencing climate changes. Recently, energetic particle precipitation (EPP) has emerged as another important source of regional climate variability from the Sun [1-6]. For instance, solar proton events (SPEs) occurring in relation to solar variabilities such as solar flares and coronal mass ejections are known to cause significant changes in ozone and other chemical constituents in the stratosphere and mesosphere $[7,8]$. Energetic electrons also precipitate into the polar atmosphere with a broad energy range from a few $\mathrm{eV}$ to $\mathrm{MeV}$, resulting from the interactions of the solar wind, the magnetosphere and the polar ionosphere, to change chemical compositions through inelastic collisions with the ambient atmospheric molecular species $\left(\mathrm{N}_{2}\right.$ and $\left.\mathrm{O}_{2}\right)$ [9-13]. The low-energy auroral electrons (1 eV-10 keV) precipitate into the lower thermosphere above about $100 \mathrm{~km}$ 
altitude and lead to a significant amount of the production of nitric oxide (NO). The resulting $\mathrm{NO}$ in the lower thermosphere descends to the lower atmosphere to be converted to nitrogen dioxide $\left(\mathrm{NO}_{2}\right)$ below $70 \mathrm{~km}$ altitude. The medium-to-high energy electrons (MEE) of 30-1000 keV can cause a direct production of $\mathrm{NO}_{\mathrm{x}}$ and hydrogen oxide radicals $\left(\mathrm{HO}_{\mathrm{x}}=\mathrm{OH}+\mathrm{HO}_{2}\right)$ in the polar middle atmosphere [14,15]. The MEE precipitation is related to relativistic electrons with the energy from several tens of $\mathrm{keV}$ to several $\mathrm{MeV}$, which originate from the radiation belts and are accelerated by wave-particle interactions during geomagnetic storms [11].

The EPP-induced $\mathrm{NO}_{\mathrm{x}}$ in the polar thermosphere and mesosphere is transported downward within the polar vortex by meridional circulation, contributing to the enhancement of $\mathrm{NO}_{\mathrm{x}}$ in the stratosphere during polar winter [16-21]. It is well known that $\mathrm{NO}_{\mathrm{x}}$ and $\mathrm{HO}_{\mathrm{x}}$ are responsible for the catalytic ozone destruction in the polar middle atmosphere. Andersson et al. [22] showed that energetic electron precipitation (EEP) can cause extremely large short-term ozone depletion by up to $90 \%$ in the altitudes of $60-80 \mathrm{~km}$ due to the enhancement of $\mathrm{HO}_{\mathrm{x}}$ by EEP. They also found that the EEP can generate ozone variations of up to $34 \%$ at $70-80 \mathrm{~km}$ altitudes on solar cycle timescales. Damiani et al. [20] showed that EPP causes, on average, upper stratospheric ozone depletion of about $10-15 \%$ on a monthly basis, which can contribute to climate variability on regional scales by influencing the thermal and dynamical aspects of the atmosphere. Seppälä et al. [4] suggested that the ozone destruction by EPP is comparable to the climate forcings by the variations of solar ultraviolet (UV) radiation. More recently, Lee et al. [21] reported that $\mathrm{NO}_{\mathrm{x}}$ can be directly produced at about $55 \mathrm{~km}$ altitude during geomagnetic storm periods in association with high-speed solar wind streams using satellite observation data.

There have also been a number of modeling studies on the atmospheric responses to EPP utilizing numerical models of the atmospheric dynamics and chemistry (e.g., [13,23-27]). These studies reported that the simulated $\mathrm{NO}_{\mathrm{x}}$ in the polar middle atmosphere by numerical models is typically underestimated compared to satellite measurements of $\mathrm{NO}_{\mathrm{x}}$. Randall et al. [23] reported that the simulated EPP-induced $\mathrm{NO}_{\mathrm{x}}$ in the polar stratosphere is underestimated by at least a factor of four. They suggested that the underestimation of EPP-induced $\mathrm{NO}_{x}$ is due to the absence of MEE in the inputs for the energetic electron precipitation used in models. In particular, recent modeling studies have shown that the model results of the polar mesospheric changes of $\mathrm{NO}_{\mathrm{x}}$ and $\mathrm{HO}_{\mathrm{x}}$ by energetic electrons can be improved by including MEE [15,28-31]. For instance, Andersson et al. [15] performed model simulations with the EPP forcing by SPEs, auroral electrons, and MEE over decadal time scales and suggested an average polar ozone variability of $12-24 \%$ in the mesosphere and $5-7 \%$ in the middle and upper stratosphere, which is significantly attributed to MEE in the total EPP forcing. Furthermore, the results of these previous studies suggest that the MEE precipitation causes not only the aforementioned chemical changes, but also dynamical changes in the polar middle atmosphere. Arsenovic et al. [28] reported that the MEE precipitation causes a temperature change of approximately $1 \mathrm{~K}$ in the polar middle atmosphere, which may result in dynamical effects as well. However, it remains uncertain to what extent this temperature change can cause these dynamical effects in the presence of global atmospheric circulation, including the polar vortex in the polar middle atmosphere. Therefore, it is important to further investigate the chemical effects and their associated dynamical changes of the MEE precipitation in the polar atmosphere, which may eventually lead to the regional climate changes. In this study, we performed a model simulation to investigate the responses of the middle atmosphere to MEE precipitation in the polar region by using the Whole Atmosphere Community Climate Model (WACCM) with MEE input over a nine-year period from 2005 to 2013. The results of the simulation will be analyzed in terms of the chemical and dynamic changes of the atmosphere in both the Northern hemisphere (NH) and Southern hemisphere (SH). 


\section{Model Simulation and Analysis}

The Whole Atmosphere Community Climate Model (WACCM) is a chemistry-coupled general circulation model developed at the National Center for Atmospheric Research (NCAR). For the chemistry module, WACCM employs the Model of Ozone and Related Chemical Tracers (MOZART), which is interactive with dynamics through transport and exothermic heating and includes chemistry associated with ion species $\left(\mathrm{O}^{+}, \mathrm{NO}^{+}, \mathrm{O}_{2}{ }^{+}, \mathrm{N}_{2}{ }^{+}\right.$, and $\mathrm{N}^{+}$) $[23,32,33]$. The neutral and ion species are simultaneously considered in the model (WACCM4 from CESM1.1), which is suitable for the simulation of climate effects by EPP. The vertical range of the model spans from the Earth's surface to $5.9 \times 10^{-6} \mathrm{~h} \mathrm{~Pa}(\sim 140 \mathrm{~km}$ geometric height). The standard horizontal resolution for this study is $1.9^{\circ}$ latitude by $2.5^{\circ}$ longitude. WACCM is capable of simulating the atmospheric responses to the EPP forcing such as SPEs and auroral electrons. The effects of auroral electrons in WACCM are parameterized with the planetary geomagnetic index $\mathrm{Kp}$, which is used to calculate the hemispheric power (HP) within the model. On the other hand, the effects of SPEs are estimated from the pre-computed atmospheric ionization rates (or ion pair production rates). $\mathrm{NO}_{\mathrm{x}}$ in the model is produced by auroral electrons and SPEs with the assumption of $1.25 \mathrm{~N}$ atoms per ion pair and with branching ratios of $0.55 / 0.7$ for $\mathrm{N}\left({ }^{4} \mathrm{~S}\right) / \mathrm{N}\left({ }^{2} \mathrm{D}\right)[9,34]$. The $\mathrm{HO}_{\mathrm{x}}$ production rate per ion pair is based on the work of [35].

In this study, we performed a numerical simulation of the EPP forcing and its effects on the middle atmosphere by implementing the MEE ionization rate into WACCM. The MEE ionization rate is calculated from the MEE precipitation model that is a part of solar forcing recommendation for the sixth Coupled Model Intercomparison Project (CMIP6). It is based on the $0^{\circ}$ detector measurements of electron flux from the Medium Energy Proton and Electron Detectors (MEPED) instrument on board the NOAA/Polar Orbiting Environmental Satellites (POES) which is known to underestimate the bounce loss cone flux as the energetic electron fluxes are strongly anisotropic with pitch angle distributions (see References $[2,36,37]$ for details). The Ap geomagnetic index-based precipitation model calculates the electron precipitation flux with the energy of 30-1000 keV from the radiation belts and then produces the ionization rates using a computationally efficient ionization parameterization for any given atmospheric composition [38]. The MEE ionization rate, therefore, primarily depends on geomagnetic activity represented by the Ap index. Figure 1 shows the monthly mean Ap and solar F10.7 indices at the top panel and monthly mean MEE and SPE ionization rates over the period 2005-2013 at the middle and bottom panels, respectively. Overall, the MEE ionization rate follows the level of the Ap index as expected, but the SPE-driven ionizations occur only sporadically and seems to be associated with an enhanced Ap index. Note that there were no SPE events around the solar cycle minimum period of 2008-2009.

To investigate the influences of MEE precipitation on the polar middle atmosphere, we used the specified dynamics WACCM (SD-WACCM). The SD-WACCM is a modified version of WACCM, in which the dynamics are constrained to the meteorological fields, including temperature, horizontal wind, and various surface parameters, all within a userdefined tolerance. Below $1 \mathrm{~h} \mathrm{~Pa}$, the model is constrained to the Goddard Earth Observing System 5 (GEOS5) meteorological reanalysis data. The GEOS5 reanalysis data includes winds, temperature, surface pressure, surface wind stress, and heat fluxes. SD-WACCM allows us to adopt the reanalysis data for a realistic representation of the atmospheric dynamics. The nudging coefficient of the reanalysis data used in this study is 0.01 [39]: that is, winds, temperature, and surface pressure are defined by a linear combination of $1 \%$ from GEOS5 and 99\% from the model. The nudging scheme is conducted below $50 \mathrm{~km}$ and the model is fully interactive above $60 \mathrm{~km}$. At the altitude between 50 and $60 \mathrm{~km}$, the nudging is linearly changed from $1 \%$ to $0 \%$. Therefore, the interactions of the chemistry and dynamics are not constrained by the 3rd party meteorological data in the mesosphere and lower thermosphere (MLT) regions. 


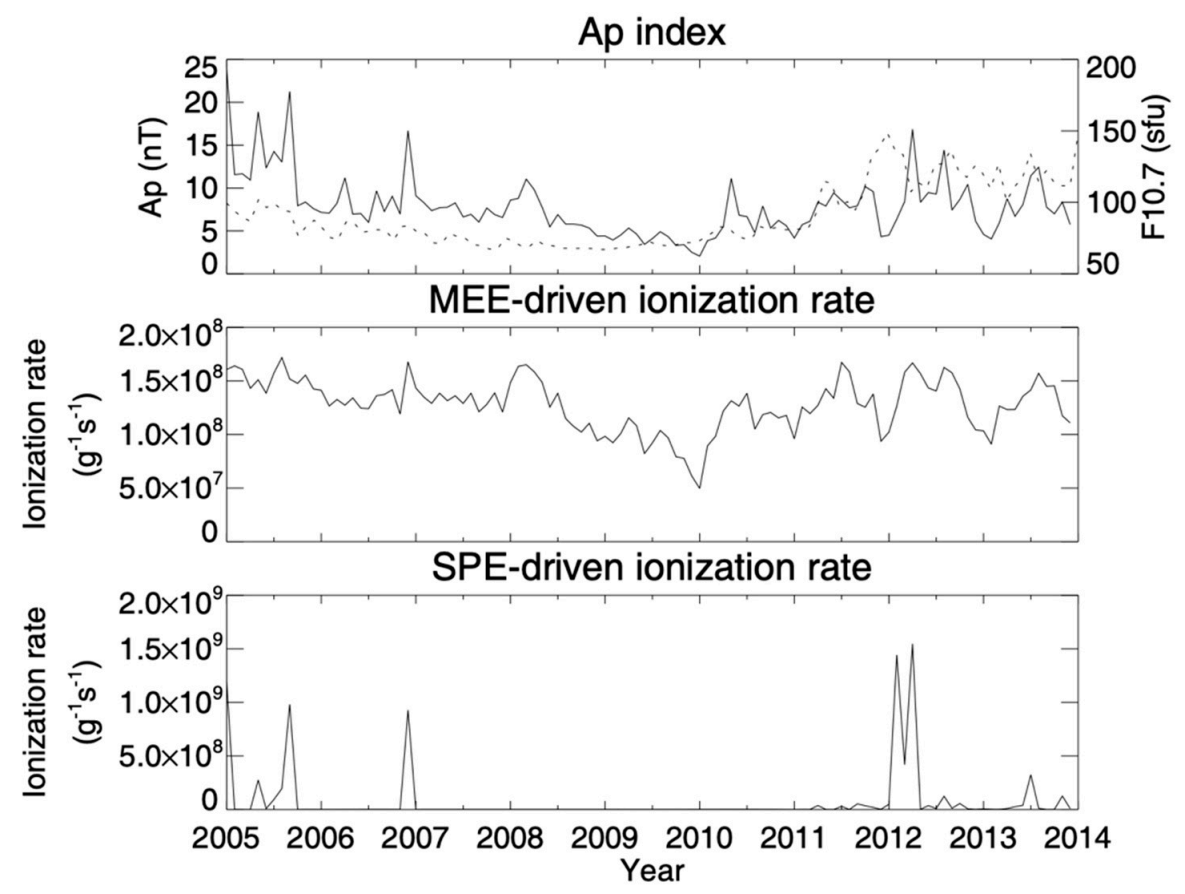

Figure 1. Monthly mean Ap (soild line) and F10.7 (dotted line) indices during the period from 2005 to 2013 are presented at the top panel. Zonally averaged ionization rates at $70 \mathrm{~km}$ altitude and $66^{\circ}$ geographic latitude are also shown in the next panels by medium-to-high energy electrons (MEE) and by solar proton event (SPE) during the study period.

In specified dynamic mode, the model dynamics are connected to the observed meteorology, which already includes particle effects. Therefore, the free-running part above $50 \mathrm{~km}$ partially includes forcing from below from the EEP effect. All simulations using SD-WACCM include EEP effects up to the stratosphere. Nevertheless, many studies have used SD-WACCM to investigate the EEP effect above the stratosphere. We wanted to see a change in the mesosphere for the MEE effect, which mostly affects in mesosphere. With this numerical model simulation, we investigated the chemical and dynamical impacts of MEE on the stratosphere and mesosphere in the polar region in terms of the spatiotemporal variations of $\mathrm{NO}_{\mathrm{x}}, \mathrm{HO}_{\mathrm{x}}$, ozone, temperature, and winds. The differences between the model runs with and without the MEE precipitation (MEE and Control runs, respectively) were estimated to study the effects of the MEE precipitation over the 2005-2013 period. The analysis of the results of the SD-WACCM simulation was carried out for the winter hemisphere (December, January, and February in the NH, and June, July, and August in the $\mathrm{SH})$.

\section{Results and Discussions}

\subsection{Chemical Changes by MEE Precipitation}

Figure 2 shows the daily mean vertical profiles of the zonal mean $\mathrm{NO}_{\mathrm{x}}$ volume mixing ratio (VMR) averaged over the polar region within the latitudes of $70^{\circ}-90^{\circ}$ in both hemispheres over the period of 2005-2013. A 10-day moving average of the daily mean vertical profiles was applied for this figure. In each hemisphere, the results of the Control (top) and MEE (middle) runs and their relative changes "(MEE-Control)/Control" (bottom) are presented in the panels. The black vertical bars at the top of each panel indicate SPEs with the energy of $10 \mathrm{MeV}$ and the intensity greater than about 10 particle flux units (pfu, or particles sr ${ }^{-1} \cdot \mathrm{cm}^{-2} \cdot \mathrm{s}^{-1}$ ). Note that no SPEs occurred during the solar minimum period of 2007-2009. The white vertical bars indicate the six major sudden stratospheric warming (SSW) events, which occurred mostly in January and February in the NH, while none took place in the $\mathrm{SH}$. This figure clearly shows that $\mathrm{NO}_{x}$ is directly enhanced by almost all SPE events in the mesosphere and stratosphere and the enhancements can reach down to 
about $25 \mathrm{~km}$ altitude. The enhancements of $\mathrm{NO}_{x}$ show very clearly different effects of the SPEs and MEE in the stratosphere. On the other hand, $\mathrm{NO}_{\mathrm{x}}$ is decreased by major SSWs in the NH. Therefore, it seems to be evident from these initial results that both SPEs and SSWs play an important role in the determination of $\mathrm{NO}_{x}$ in the polar middle atmosphere. Comparing the MEE runs with the Control runs, $\mathrm{NO}_{\mathrm{x}}$ in the MEE runs is significantly larger than in the Control run with a significant year-to-year variability, particularly in the mesosphere in both hemispheres. This result shows that the MEE precipitation enhances mesospheric $\mathrm{NO}_{\mathrm{x}}$, not only in winter, but in all seasons. Note that the MEE effects seem to reach down to the slightly lower altitudes in the $\mathrm{SH}$ than in the $\mathrm{NH}$, which may be associated with the influence of the strong and stable polar vortex in the SH. In particular, the enhancement of stratospheric $\mathrm{NO}_{x}$ may be related to the indirect effect by downward transported air within the polar vortex $[40,41]$.
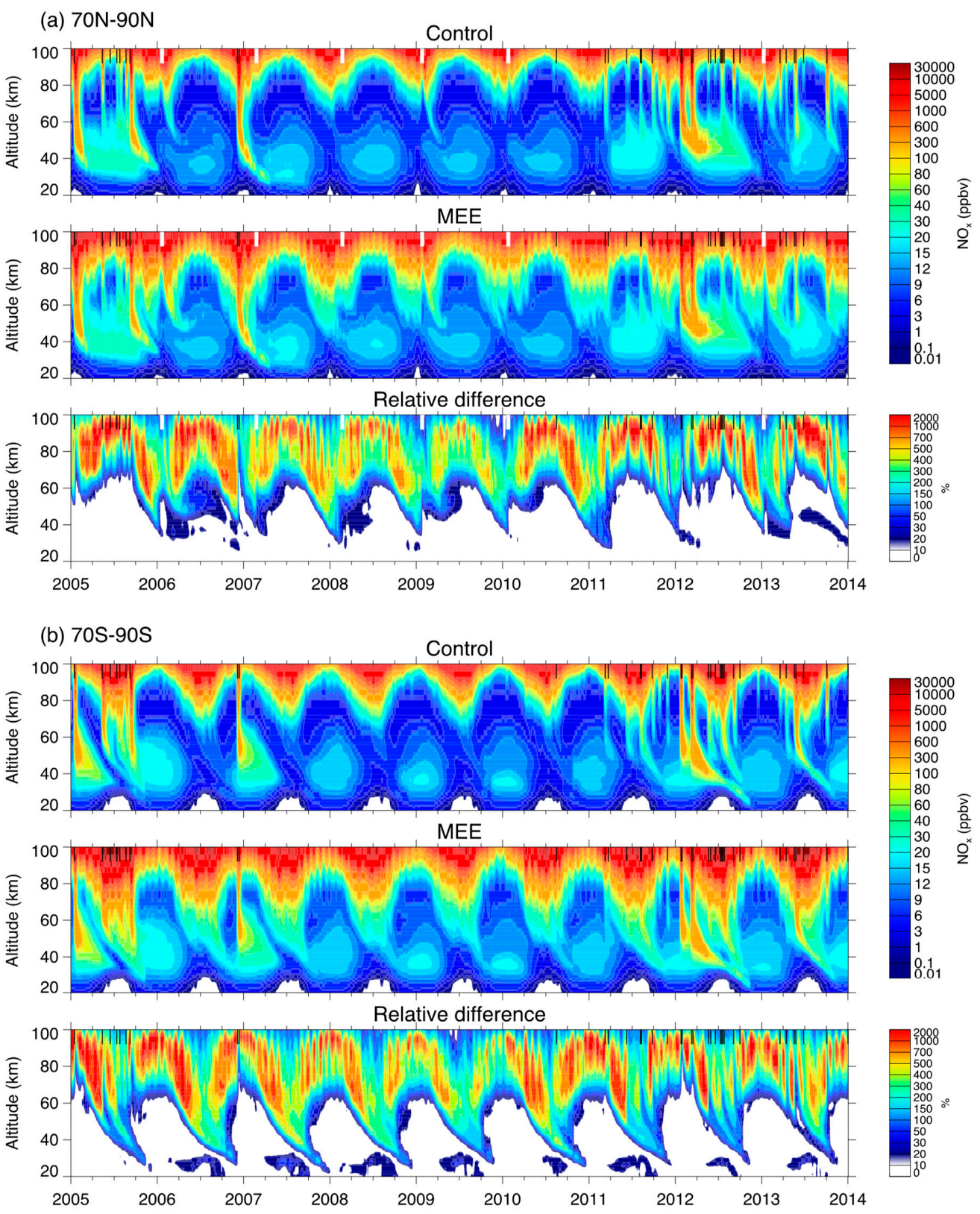

Figure 2. The vertical profiles of $\mathrm{NO}_{x}$ volume mixing ratio (VMR) averaged over the latitude range of $70^{\circ}-90^{\circ} \mathrm{N} / \mathrm{S}$ in the middle atmosphere from the control and MEE runs and their relative differences ((MEE-Control)/Control) during the period from 2005 to 2013 are presented. The 10-day moving average is applied for these figures. The black short lines at the top of each panel indicate the occurrences of solar proton events (SPEs) and the white short lines indicate the stratospheric sudden warming (SSW). 
Figure 3 shows the seasonal variations of the MEE effects by the relative changes in the daily mean profiles for $\mathrm{NO}_{\mathrm{x}}, \mathrm{HO}_{\mathrm{x}}$, and ozone VMRs in the $\mathrm{NH}$ (top panels) and $\mathrm{SH}$ (bottom panels). Note that the winter months are centered in the figure for both hemispheres. Positive differences in the left and middle panels indicate the enhanced $\mathrm{NO}_{\mathrm{x}}$ and $\mathrm{HO}_{\mathrm{x}}$ due to the MEE precipitation included in the MEE runs and negative differences at the right panels indicate the corresponding ozone depletion in the MEE runs. $\triangle \mathrm{NO}_{\mathrm{x}}$ in the left panels shows the largest differences (up to about 1600\% increase) in the upper mesosphere in summer but it becomes smaller (less than 200\%) and extended down to the lower stratosphere in winter. In particular, the downward transport of $\mathrm{NO}_{\mathrm{x}}$ persists until late spring in the Southern hemisphere. In the northern polar winter, on the other hand, the downward transport is much weaker than in the southern winter, most likely resulting from the frequent occurrence of SSWs [42]. Randall et al. [23] also showed that the SDWACCM simulation underestimates stratospheric $\mathrm{NO}_{x}$ from the comparison with satellite observation and attributed it to too little $\mathrm{NO}_{x}$ production by EPP and/or insufficient transport from the MLT, which may probably be due to the lack of MEE precipitation in the model. Andersson et al. [15] used free-running dynamics WACCM, instead of SD-WACCM, and showed similar results in the mesospheric responses of $\mathrm{NO}_{\mathrm{x}}, \mathrm{HO}_{\mathrm{x}}$, and ozone to MEE in the southern winter.
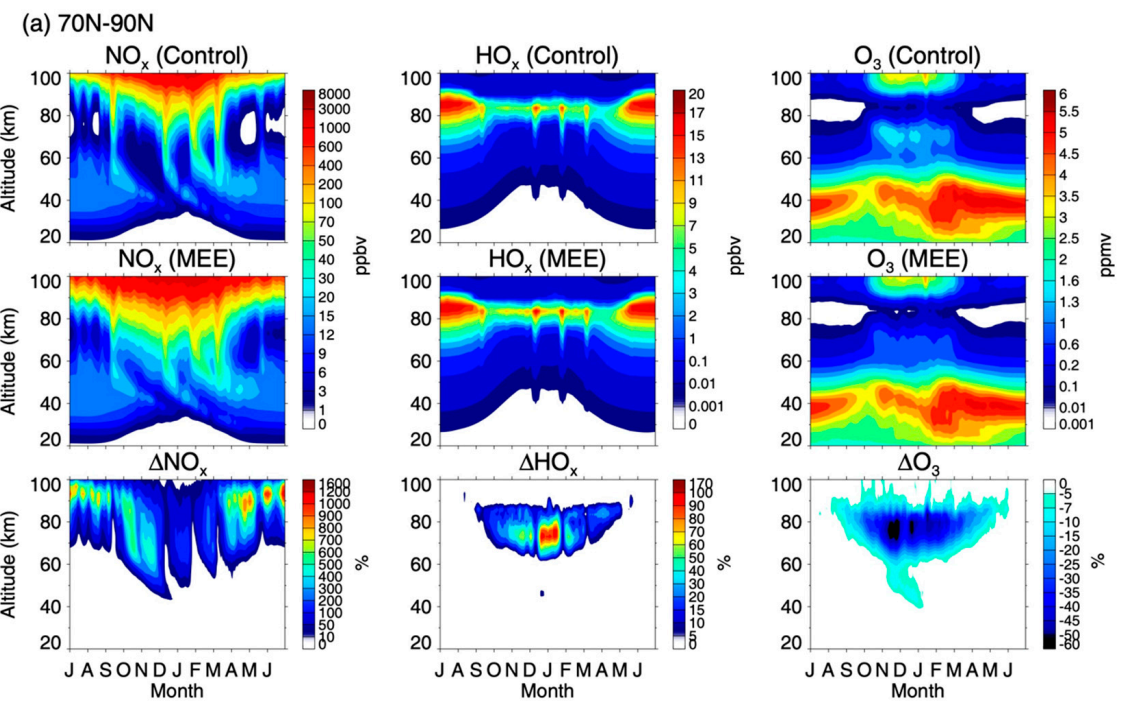

(b) $70 \mathrm{~S}-90 \mathrm{~S}$
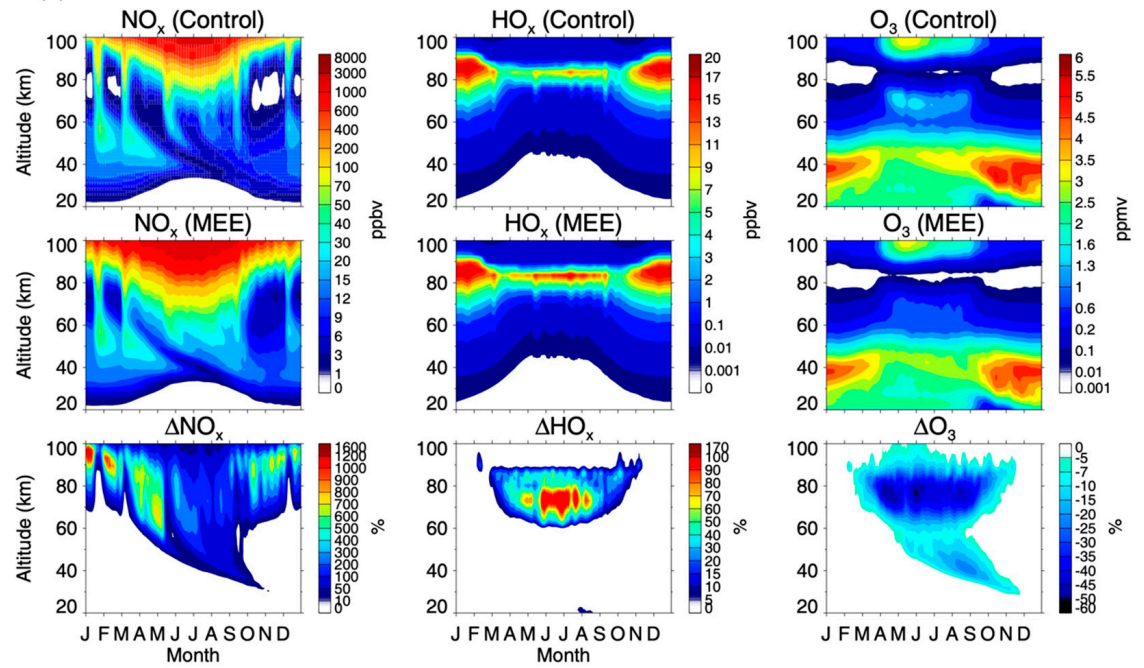

Figure 3. Seasonal variations of the daily zonal mean height profiles of $\mathrm{NO}_{x}$ (left), $\mathrm{HO}_{\mathrm{x}}$ (middle), $\mathrm{O}_{3}$ (right) VMRs are presented from the control and MEE runs and their relative changes ((MEE-Control)/Control). All values are averaged in the latitude range of $70^{\circ}-90^{\circ} \mathrm{N} / \mathrm{S}$ during the whole period from 2005 to 2013 with the application of a 7-day moving average. 
$\Delta \mathrm{HO}_{\mathrm{x}}$ in the middle panels of Figure 3 shows nearly opposite seasonal variation to $\Delta \mathrm{NO}_{\mathrm{x}}$ and relatively limited differences occurring only in the upper mesosphere. The largest differences (up to about $170 \%$ increase) appear in the altitude of $70-80 \mathrm{~km}$ in winter but there is no difference in summer, which seems to be related with the fact that the background $\mathrm{HO}_{\mathrm{x}}$ is much larger in summer than in winter. Even though $\mathrm{HO}_{\mathrm{x}}$ is also produced in summer, the relative changes are negligibly small due to much larger background density. The MEE effects on $\mathrm{HO}_{\mathrm{x}}$ seem to be a little larger in the southern winter than in the northern winter. The MEE effects on ozone are presented in the right panels of Figure 3. The ozone changes from the MEE precipitation during winter appear to be mainly associated with $\mathrm{HO}_{x}$ in the mesosphere (which results in up to about $60 \%$ ozone depletion in both hemispheres) but with $\mathrm{NO}_{x}$ in the stratosphere (which results in up to about $10-15 \%$ in the $\mathrm{SH}$ but negligible effect in the $\mathrm{NH}$ ). Note that, on average, almost no stratospheric ozone depletion is found in the $\mathrm{NH}$, which resembles the changes in $\mathrm{NO}_{\mathrm{x}}$. This may also reflect the large year-to-year variability in the northern stratosphere, shown in Figure 2. The result of the hemispheric difference of the stratospheric ozone changes agrees with Arsenovic et al. [28] which used the SOCOL3-MPIOM chemistryclimate model to investigate MEE influence on the stratosphere and the mesosphere during 2002-2010 period.

In order to further investigate the associations between the ozone depletion and $\mathrm{NO}_{x}$ and $\mathrm{HO}_{\mathrm{x}}$ in Figure 3, we present the differences of $\mathrm{NO}_{\mathrm{x}}, \mathrm{HO}_{\mathrm{x}}$, and ozone between the control and MEE runs in the polar coordinate in Figures 4 and 5. In Figure 4, the differences of the $\mathrm{HO}_{\mathrm{x}}$ and ozone VMRs averaged over $65-75 \mathrm{~km}$ altitude range are displayed in the $\mathrm{NH}$ (left panels) and SH (right panels) during winter months. The larger enhancement of $\mathrm{HO}_{\mathrm{x}}$ in the SH seems to be associated with the South Atlantic Anomaly (SAA) [28]. The SAA is the region where the inner Van Allen radiation belt approaches most closely to the Earth's atmosphere and therefore, the EEP flux is intensified near the SAA. The intensified EEP flux causes the hemispheric asymmetry of the EEP-induced $\mathrm{HO}_{\mathrm{x}}$, as seen in the top panels of Figure 4. The mesospheric $\mathrm{HO}_{\mathrm{x}}$ increases by up to approximately $1 \mathrm{ppbv}$ and $1.5 \mathrm{ppbv}$ in the $\mathrm{NH}$ and $\mathrm{SH}$, respectively. The increased $\mathrm{HO}_{\mathrm{x}}$ causes the loss of mesospheric ozone by up to about $0.4 \mathrm{ppmv}$ and $0.6 \mathrm{ppmv}$ in the northern and southern polar regions, respectively. Although the regions of the maximum changes of both $\mathrm{HO}_{\mathrm{x}}$ and $\mathrm{O}_{3}$ are similarly shifted, for example, towards the SAA region in the $\mathrm{SH}$, there are significant differences. The overall morphology of the $\mathrm{HO}_{x}$ changes seems to follow the auroral region where large EEPs are expected, but the $\mathrm{O}_{3}$ changes do not show auroral-oval like morphology since the lifetime of ozone is long enough to spread into the polar region in the absence of sunlight. Figure 5 shows the differences between $\mathrm{NO}_{x}$ and $\mathrm{O}_{3} \mathrm{VMRs}$ averaged over the upper stratospheric altitudes of $40-50 \mathrm{~km}$. The upper stratospheric $\mathrm{NO}_{\mathrm{x}}$ is enhanced by up to $9 \mathrm{ppbv}$ in the $\mathrm{SH}$ but only $4 \mathrm{ppbv}$ in the $\mathrm{NH}$. The corresponding ozone depletion also shows similar hemispheric differences: $0.25 \mathrm{ppmv}$ and $0.46 \mathrm{ppmv}$ in the $\mathrm{NH}$ and $\mathrm{SH}$, respectively. This hemispheric difference in the stratosphere is much greater than in the mesosphere and it may be related to the characteristics of the atmospheric dynamics associated with SSWs in the polar region. Note that the overall morphologies of the $\mathrm{NO}_{\mathrm{x}}$ and $\mathrm{O}_{3}$ changes are notably distorted in the $\mathrm{NH}$ while they remain to be symmetric in the $\mathrm{SH}$, reflecting the hemispheric differences of the polar vortex. It is noteworthy that the mesospheric $\mathrm{HO}_{\mathrm{x}}$ changes in Figure 4 are distributed around the geomagnetic poles, while the stratospheric $\mathrm{NO}_{x}$ changes in Figure 5 are distributed around the geographic poles. This clearly shows that the mesospheric $\mathrm{HO}_{\mathrm{x}}$ changes are directly produced by EEP guided by the geomagnetic field lines, while the stratospheric $\mathrm{NO}_{x}$ changes are strongly affected by atmospheric dynamics that are closely associated with the polar vortex around the geographic pole. To summarize the chemical effects by MEE precipitation, the ozone losses are mostly associated with $\mathrm{HO}_{\mathrm{x}}$ in the mesosphere but with $\mathrm{NO}_{\mathrm{x}}$ in the lower mesosphere and the stratosphere in polar winter. 


\section{$65-75 \mathrm{~km}$}
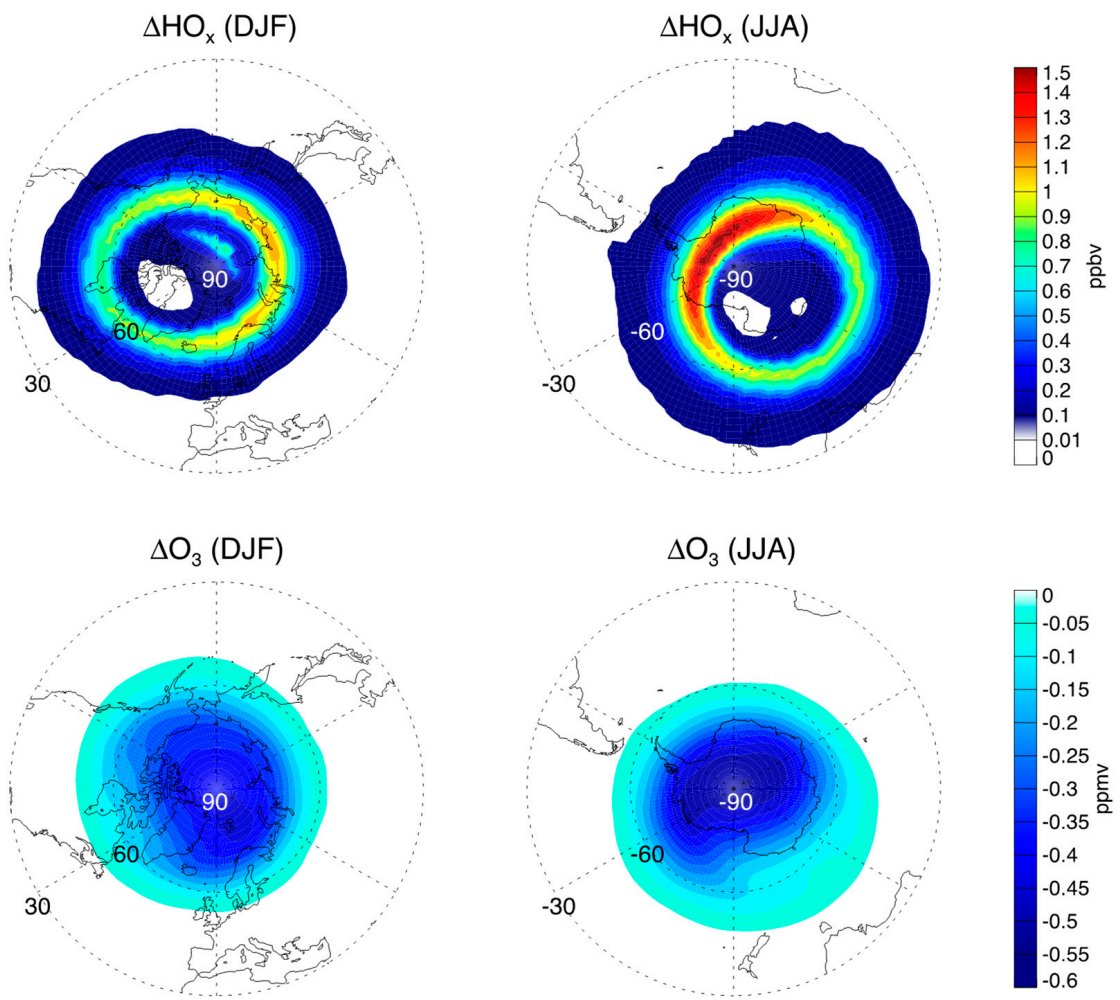

Figure 4. The differences (MEE-Control) of the mean HOx and ozone are presented in the altitude range of 65-75 km in the northern winter (December, January, February; DJF) and southern winter (June, July, August; JJA) during the period from 2005 to 2013.

\section{$40-50 \mathrm{~km}$}
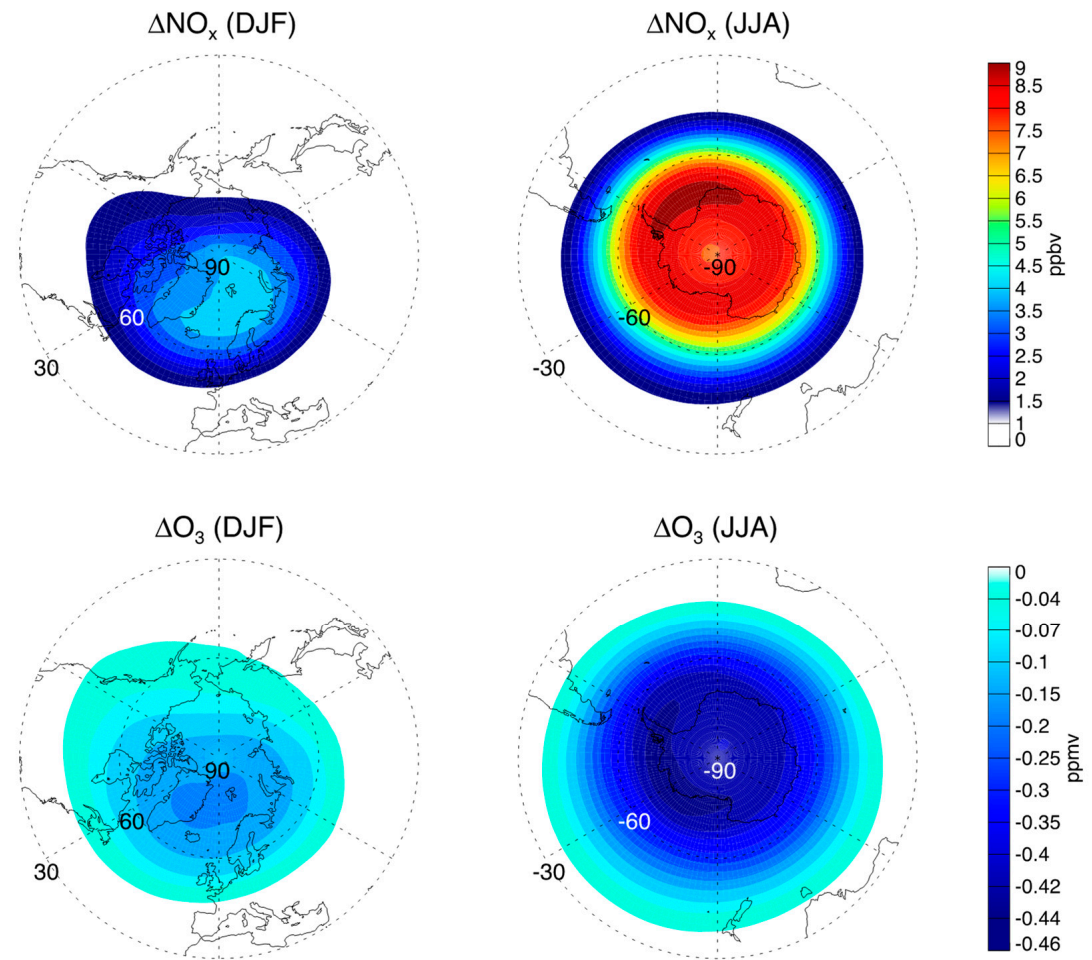

Figure 5. The differences (MEE-Control) of the mean NOx and ozone are presented in the altitude range of 40-50 km in the northern winter (December, January, February; DJF) and southern winter (June, July, August; JJA) during the period from 2005 to 2013. 


\subsection{Dynamic Changes Connected with MEE Induced Ozone Loss}

Ozone loss in the middle atmosphere can affect the atmospheric temperature by direct radiative energy transfer. During polar winter, ozone acts to cool the atmosphere by emitting infrared radiation (i.e., radiative cooling) in the stratosphere and the mesosphere [43-46]. Figure 6 shows the radiative cooling rates of the ozone for non- local thermodynamic equilibrium (LTE) conditions caused by radiative processes alone [43]. The ozone cooling occurs in the altitude range of $40-90 \mathrm{~km}$ for polar winter (PW) conditions. The cooling rate is maximized at around $60 \mathrm{~km}$ altitude but very small in the upper stratosphere and the upper mesosphere. In the lower thermosphere above $90 \mathrm{~km}$, the ozone absorption of outgoing radiation exceeds the radiative cooling effect, which results in a negative cooling rate. With these characteristics of the cooling rate by ozone, it is expected that the EPP-induced ozone loss results in relative warming in the most part of the mesosphere due to reduced cooling, but relative cooling in the upper mesosphere and lower thermosphere due to reduced warming during polar winter. Given that the mesospheric ozone losses lead to changes of the radiative forcing in the polar region, the resulting temperature changes may affect the dynamics of the middle atmosphere. In other words, as a consequence of the temperature changes, the pole-to-pole meridional circulation, as well as the zonal wind, can be changed in the polar middle atmosphere. Furthermore, even slight changes of the meridional circulation may lead to adiabatic heating or cooling in the polar region, which can further change the temperature in the middle atmosphere [47,48].

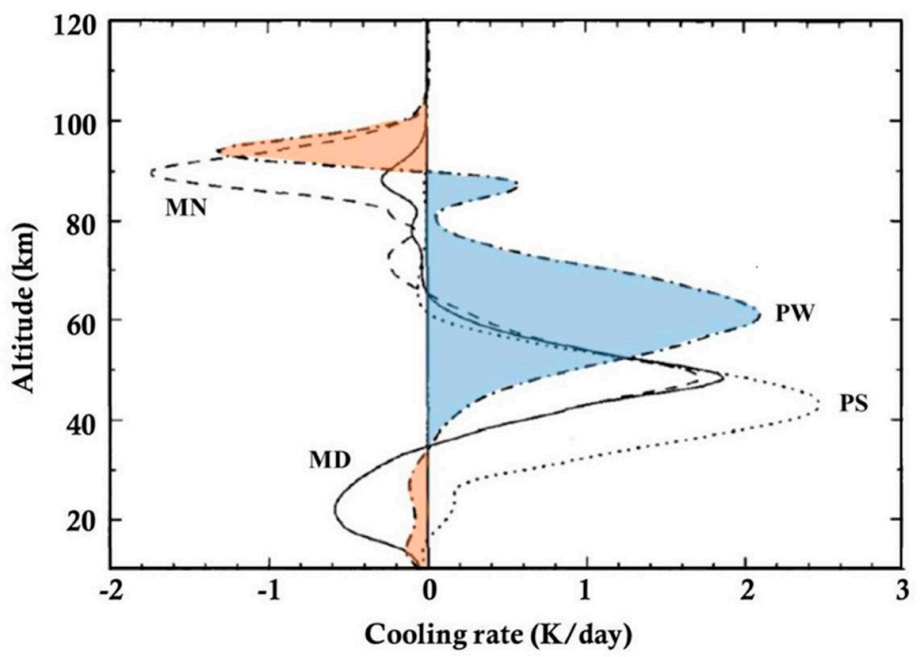

Figure 6. Cooling rates of ozone for non-local thermodynamic equilibrium (LTE) conditions caused by a radiative process are presented in the altitude region of 10-120 km for mid-latitude day (MD, solid) and night (MN, dashed) and for polar winter (PW, dot-dashed) and summer (PS, dotted). This figure is adopted from [43].

In order to investigate the dynamic changes by MEE-induced ozone loss, we examined the changes in temperature and wind. For this investigation, we focused on the dynamic changes in the southern winter to exclude SSW effects since SSW rarely occurs in the SH. Figure 7 shows the monthly differences in the zonal mean values of ozone, temperature, and zonal wind between control and MEE runs from May to August in the southern winter over the period 2005-2013. The residual-mean vertical wind profiles averaged over $70^{\circ} \mathrm{S}-90^{\circ} \mathrm{S}$ from control (black) and MEE (red) runs are also presented at the bottom panels. Three ozone layers in the polar winter shown in Figure 3 exhibit different behaviors from May to August. The ozone loss in the secondary ozone layer (90-105 km) gradually decreases from May to August; the ozone loss in the tertiary ozone layer $(65-80 \mathrm{~km})$ seems steady; but the ozone loss in the primary ozone layer in the upper stratosphere gradually increases and expands to lower altitude with decreasing peak altitude. Therefore, the largest ozone loss in August occurs in the upper stratosphere. In the second-row panels of 
Figure 7, the temperature changes show clear warming in the lower mesosphere (50-70 km altitude) and cooling in the upper mesosphere above about $70 \mathrm{~km}$ altitude in the $\mathrm{SH}$. Compared with the ozone changes, the temperature changes are narrowly restricted to the polar region within $70^{\circ} \mathrm{S}$ latitude. It should be noted that temperature differences between control and MEE runs should be ignored in the stratosphere, since SD-WACCM is nudged towards meteorological re-analysis data at the height from the surface to $50 \mathrm{~km}$. The largest temperature changes occur in May and August, but they are relatively small in June and July. The 9-year mean temperature changes occur in the range of $\pm 1.5 \mathrm{~K}$ in the polar middle atmosphere. The differences of zonal wind are shown in the third-row panels of Figure 7. The mesospheric zonal wind is reduced in the southern polar region, most distinctively in May and August but relatively small in June and July as in temperature changes. The bottom panels of Figure 7 shows the downward motions of the Transformed Eulerian Mean (TEM) circulation $\left(\overline{\mathrm{w}}^{*}\right)$ averaged over the latitudes of $70^{\circ} \mathrm{S}-90^{\circ} \mathrm{S}$ for the control (black lines) and MEE (red lines) runs. More detailed descriptions of the TEM circulation $\left(\overline{\mathrm{w}}^{*}\right)$ can be found in Andrews et al., [49]. The downward motion in the MEE run is generally smaller than in the control run (except for July), which may imply that the MEE precipitation seems to work to reduce downward motion in winter. Note that the negligible difference in July may be associated with the smallest changes of temperature and zonal wind in July. The reduced downward motion in the MEE run should indicate the reduced downward transport of $\mathrm{NO}_{\mathrm{x}}$ in the middle atmosphere.
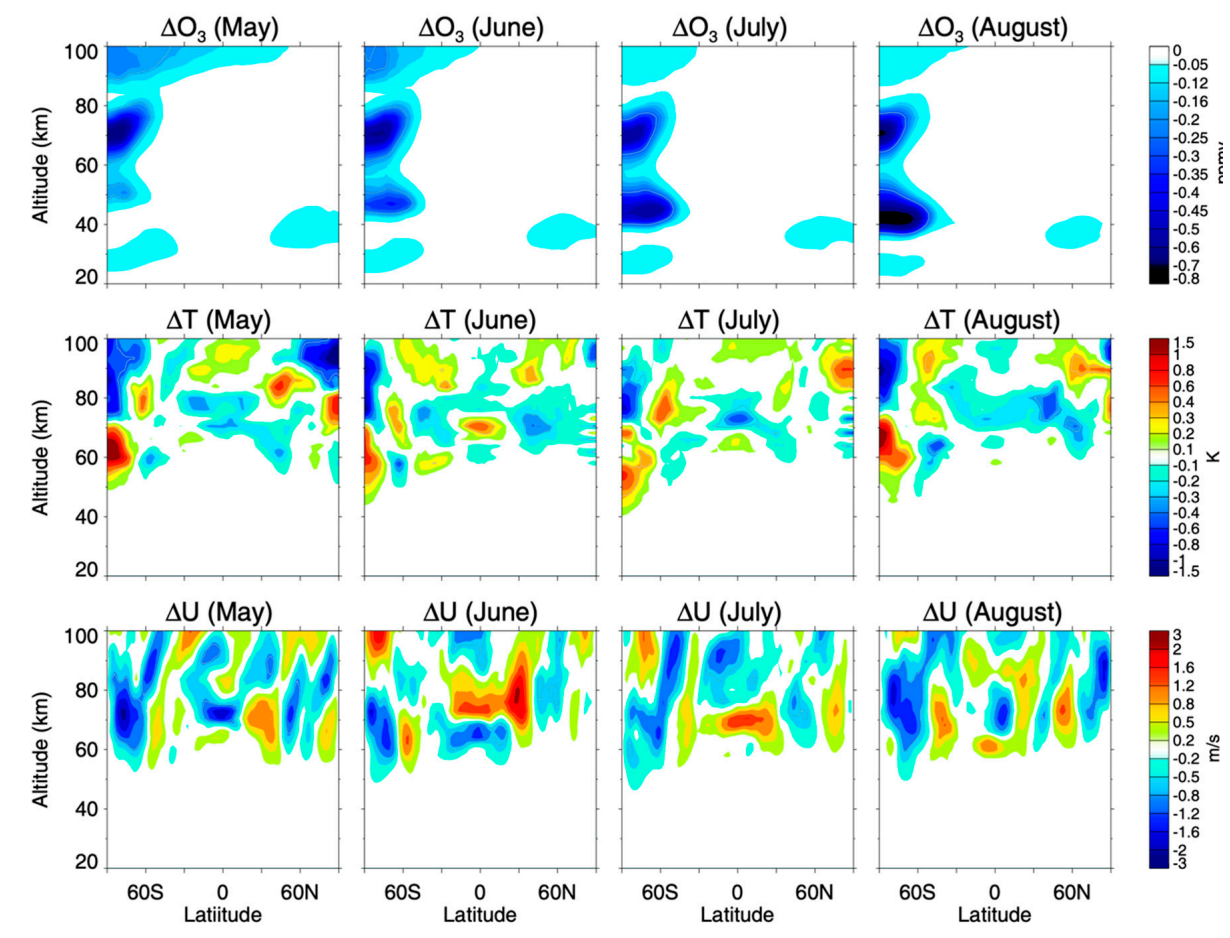

$\Delta \mathrm{U}$ (August)
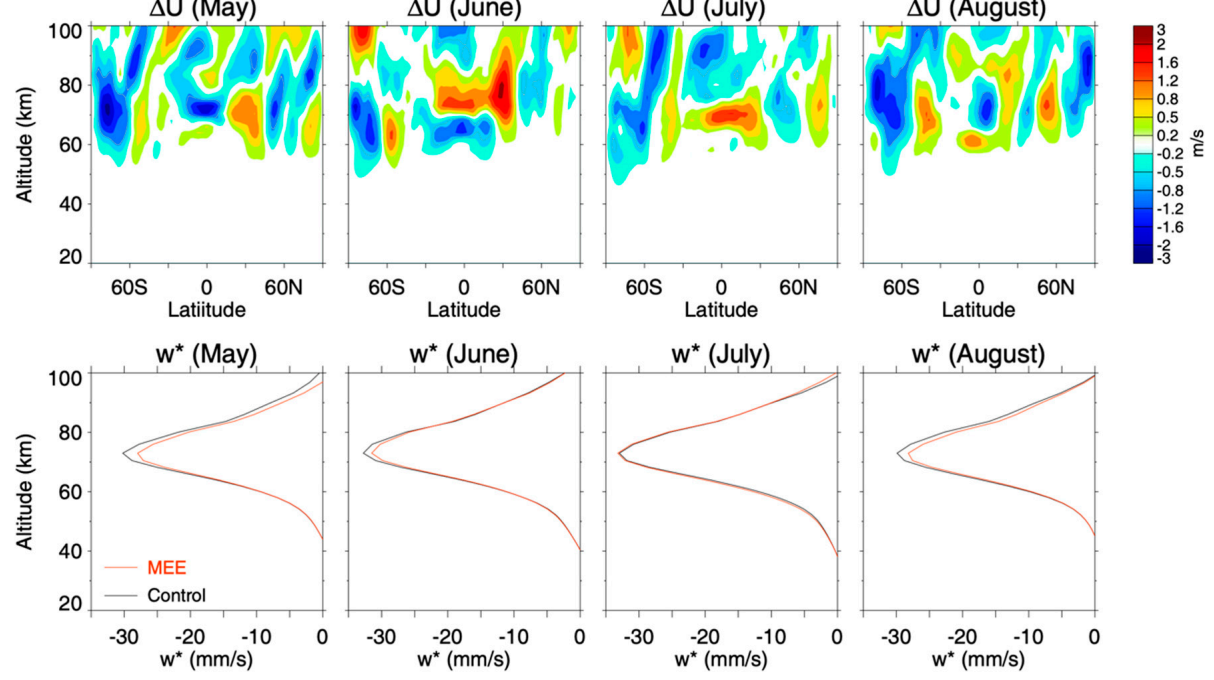

Figure 7. Monthly mean latitudinal variations of the differences (MEE-Control) in the zonal mean ozone (top panels), temperature (second panels), and zonal wind (third panels) in the altitude range of 20-100 km from May to August in the southern winter during 2005-2013. Also shown at the bottom panels are the height profiles of the vertical wind averaged over the latitudes of $70^{\circ} \mathrm{S}-90^{\circ} \mathrm{S}$. The black and red lines indicate the downward motions in the control and MEE runs, respectively. 
Figure 8 shows the relative change of carbon monoxide $(\mathrm{CO})$ as a dynamic tracer averaged over the latitudes of $70^{\circ}-90^{\circ}$ in both hemispheres over the period of 2005-2013. A 10-day moving average of the daily mean height profiles was applied in the figure. The $\mathrm{CO}$ in the $\mathrm{SH}$ is significantly reduced in the lower mesosphere $(60 \sim 70 \mathrm{~km})$ from the middle of May and decreases down to $40 \%$ in the stratosphere $(\sim 30 \mathrm{~km})$ in November (i.e., spring). Also note that the height of the $\mathrm{CO}$ change continuously decreases from about $70 \mathrm{~km}$ in May to about $30 \mathrm{~km}$ in November. On the other hand, the $\mathrm{CO}$ changes in the $\mathrm{NH}$ are relatively small probably due to the unstable polar vortex. $\mathrm{CO}$, as a dynamic tracer, is assumed to represent the characteristics of the transport of the air in the polar middle atmosphere. Since the CO mixing ratio increases with height, its reduction in the lower mesosphere suggests weaker downward transport of the air, which is consistent with the result from the behavior of the TEM circulation $\left(\overline{\mathrm{w}}^{*}\right)$. As the WACCM simulations (with or without MEE precipitation) are fully interactive in the MLT region, however, the reduced transport in the MEE run does not necessarily mean that the enhanced middle atmospheric $\mathrm{NO}_{\mathrm{x}}$ is not caused by downward transport. Although the downward transport decreases in the MEE run, the significantly enhanced $\mathrm{NO}_{\mathrm{x}}$ by MEE precipitation in the MLT region is still transported downward to the lower mesosphere and the stratosphere to increase $\mathrm{NO}_{\mathrm{x}}$ in the middle atmosphere as shown in Figures 2 and 3.
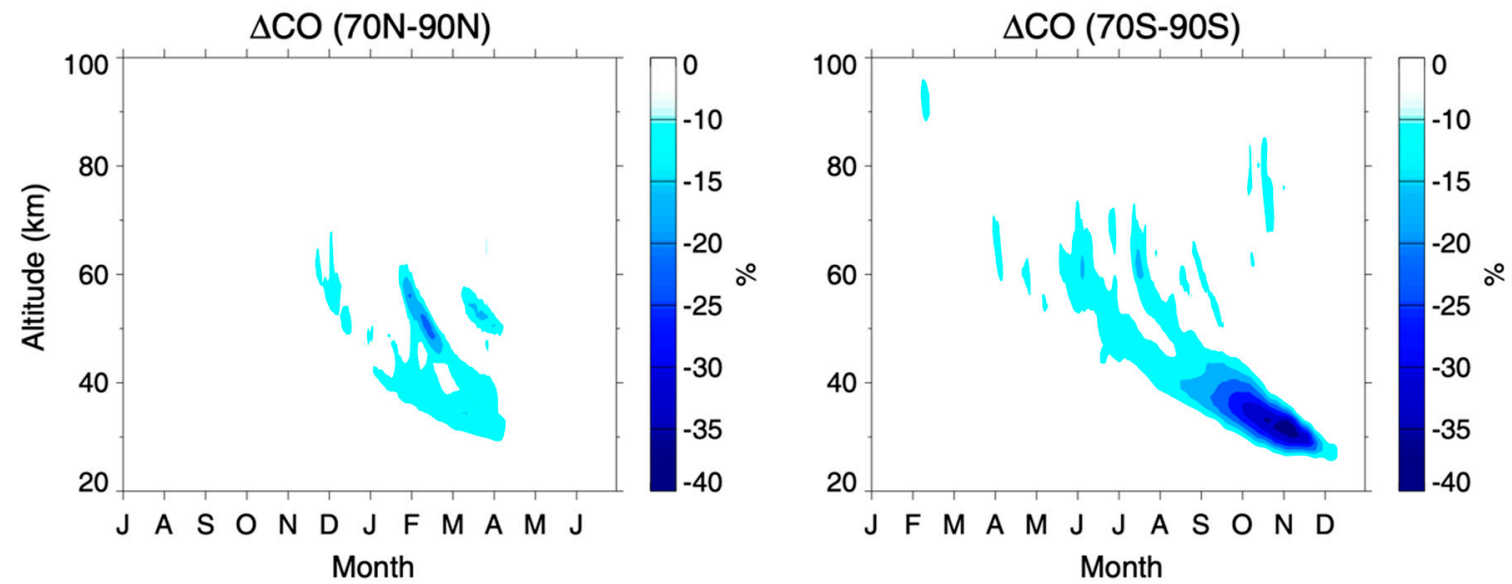

Figure 8. Seasonal variations of the relative changes ((MEE-Control)/Control) are presented for the zonal mean volume mixing ratios of $\mathrm{CO}$ averaged in the latitude range of $70^{\circ}-90^{\circ} \mathrm{N} / \mathrm{S}$ from 2005 to 2013. The 7-day moving average was applied.

Figure 9 shows the temperature (left) and zonal wind (right) differences between control and MEE runs in the southern winter (JJA) in the polar coordinate. The mean temperature and zonal wind differences are presented in the upper $(75-85 \mathrm{~km})$ and lower $(60-70 \mathrm{~km})$ mesosphere, respectively. Note that the 3-month averaged temperature changes are negative near the geographic pole but largely positive around the pole in the upper mesosphere. On the other hand, it is the opposite in the lower mesosphere: positive at the pole but largely negative around the pole. The zonal wind changes are also significantly different in the upper and lower mesosphere. The temperature and zonal wind changes are up to about $1 \mathrm{~K}$ and $2 \mathrm{~m} / \mathrm{s}^{-1}$, respectively, which appears to indicate that the impact of dynamic changes by the MEE precipitation is small. The previous studies also reported temperature changes of 1-6 K by EPP in the polar upper stratosphere and lower mesosphere. Baumgaertner et al. [6] showed the warming by up to $5 \mathrm{~K}$ in the polar winter mesosphere from 44-year transient simulation with EPP and no EPP. A previous study [50] found that high geomagnetic activity leads to warming by up to $6 \mathrm{~K}$ in the upper stratosphere and cooling by down to $-4 \mathrm{~K}$ in the lower stratosphere. Meraner and Schmidt [1] also investigated the climate impact when EPP induced-ozone loss is strong in the stratosphere and mesosphere. They found that the radiative forcing of mesospheric ozone loss leads to negligible temperature changes less than $1 \mathrm{~K}$. Arsenovic et al. [28] investigated the influence of MEE precipitation on the atmosphere over the period 2002-2010 using the 
chemistry-climate model. Their results showed that the temperature differences with and without MEE in the upper stratosphere and lower mesosphere are small $(\sim 1 \mathrm{~K})$ and the zonal wind differences are also only up to $2 \mathrm{~m} / \mathrm{s}^{-1}$ in the $\mathrm{SH}$, which are similar to our results. While the ozone loss by MEE precipitation is significant, as much as $60 \%$ in the mesosphere and $25 \%$ in the stratosphere, the corresponding changes of the temperature and zonal wind are small. As it turns out in the following section, however, the temperature changes can be significant as much as $11 \mathrm{~K}$, but the averaging process for the 9-year study period cancels out to make it small. That is, the reason for the small changes of the average temperature and zonal wind seems to be related to the large year-to-year variability of the temperature changes during the study period. This will be discussed further in the next section.
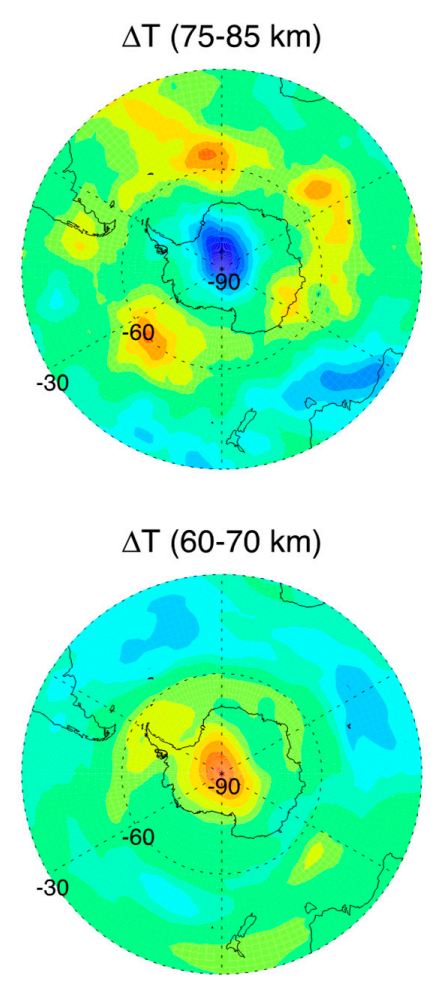
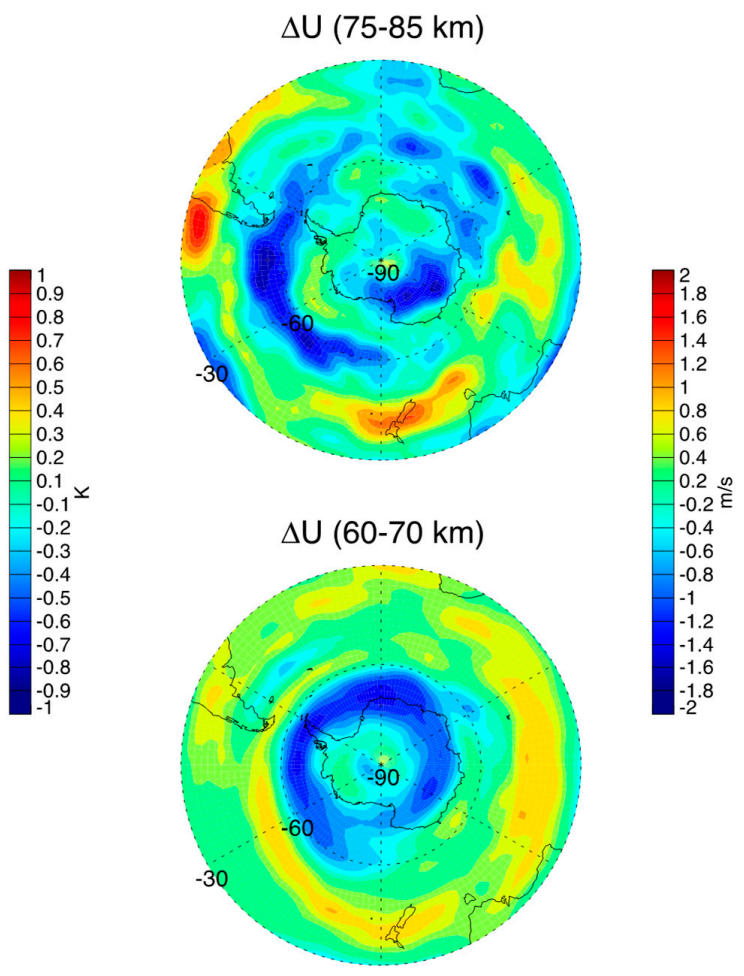

Figure 9. The differences (MEE-Control) of the temperature and zonal wind are presented in the altitude range of 75-85 $\mathrm{km}$ (top) and 60-70 km (bottom) during southern winter (JJA) from 2005 to 2013.

\subsection{Temperature Changes in the Mesosphere}

In order to further investigate the association of the temperature changes with the ozone loss in the mesosphere, Figure 10 shows the differences of ozone and temperature between control and MEE runs in the altitude ranges of 50-100 km in the southern polar winter $\left(70^{\circ} \mathrm{S}-90^{\circ} \mathrm{S}\right)$ during the three-month period of June, July, and August from 2005 to 2013. A 10-day moving average of the daily mean values was applied for this figure. The temperature changes tend to be warming below about $70 \mathrm{~km}$ altitude, but mostly cooling above the altitude, which is consistent with the mean temperature changes for the 9-year period of the study in Figures 7 and 9. However, the temperature changes in Figure 10 are significantly greater than the mean temperature changes ( $\pm 11 \mathrm{~K}$ vs. $\pm 1.5 \mathrm{~K})$. Furthermore, the temperature changes are highly variable, especially in the lower mesosphere, which results in small mean values for the 9-year period. It is also found that the variability of the temperature changes seems to show geomagnetic activity dependency. The lower mesospheric temperature changes are mostly warming by up to $11 \mathrm{~K}$ during the declining and rising phases of solar cycle with relatively high geomagnetic activity but cooling (up to $-11 \mathrm{~K}$ ) at around the solar minimum period with relatively low geomagnetic activity 
(please see Ap and F10.7 indices in Figure 2). In particular, regarding the lower mesospheric cooling at around the solar minimum with low geomagnetic activity, it was found that the noticeable ozone increases occurred in the lower mesosphere in 2009 (in other words, the ozone loss by MEE is reduced when the geomagnetic activity is low). The increased ozone acts to decrease the temperature by enhanced radiative cooling. However, this ozone increase may not be enough to explain the cooling found in Figure 10, but other factors such as the adiabatic processes by meridional circulation may also be involved in the temperature changes. For example, the suppressed downward transport can reduce adiabatic heating to cause cooling in the lower mesosphere. In fact, the lower mesospheric ozone increase can be explained by the reduced downward transport of the ozone-poor air from the higher altitude.

(a) $\Delta \mathrm{O}_{3}$

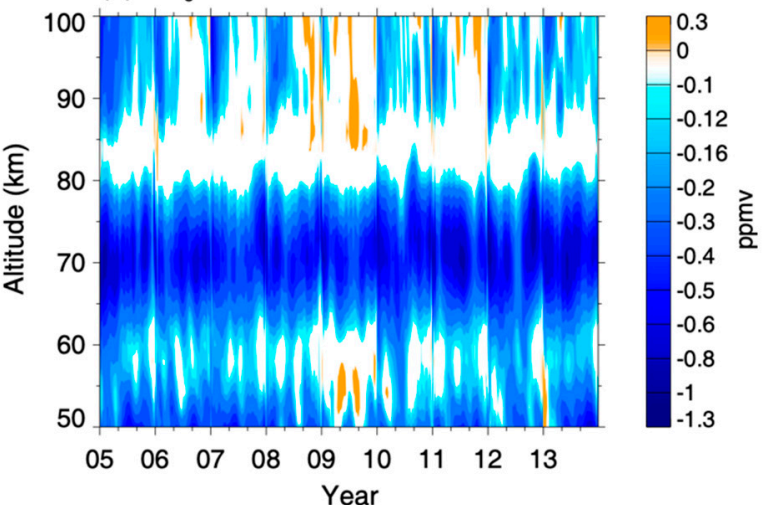

(b) $\Delta \mathrm{T}$

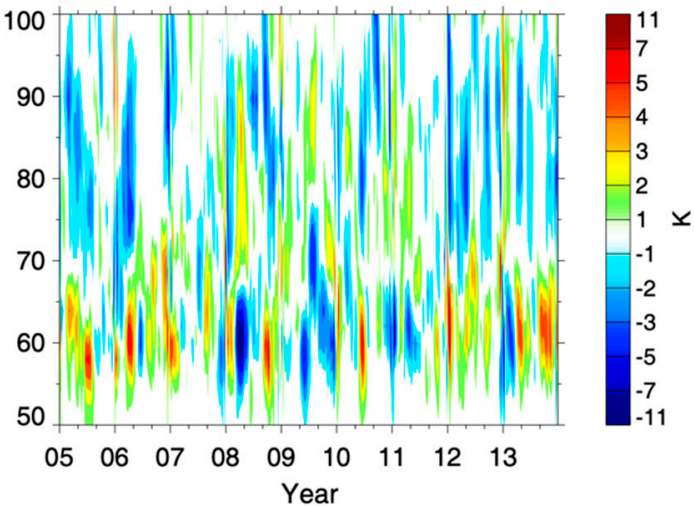

Figure 10. The height profiles of the differences (MEE-Control) in the zonal mean ozone and temperature averaged over the latitude range of $70^{\circ} \mathrm{S}-90^{\circ} \mathrm{S}$ are presented in the altitude range of 50-100 km during southern winter (June, July and August) for the entire study period from 2005 to 2013. The 10-day moving average was applied.

Figures 11 and 12 present the ozone and temperature changes displayed with the differences of residual mean velocity vector during southern polar winter for low geomagnetic activity (June 2008, July 2009, and August 2009) and for high geomagnetic activity (June 2005, July 2005, and August 2013), respectively. First of all, the two figures show nearly opposite height distributions of the temperature changes in the polar region. Although the temperature changes in Figure 12 show similar height distribution to Figure 7 (but with much larger magnitude), Figure 11 shows the opposite height distribution of the temperature changes to the 9-year mean in Figure 7. Note that the ozone changes in Figure 11 are for the most part smaller than in Figure 12. This indicates that the radiative effects by ozone loss should be smaller in Figure 11 than in Figure 12. Considering the differences of the residual mean velocities, the lower mesospheric cooling in Figure 11 may be associated not only with the radiative effects of ozone but also with the adiabatic effects of reduced downward transport or upwelling air. In the polar lower mesosphere $(\sim 60 \mathrm{~km})$, the meridional circulation changes show upward motion or weak downward motion, which induces noticeable cooling in the southern winter. In the polar upper mesosphere, however, the circulation changes generally show stronger downward motion, which induces warming by adiabatic heating. The temperature changes in Figure 12 must also be affected by adiabatic effects in addition to the radiative effects. In other words, it shows warming in the lower mesosphere by downward motion but cooling in the polar middle and upper mesosphere by upward motion or reduced downward motion. The MEE precipitation generally produces strong downward motion in the polar lower mesosphere, but rather weak downward or upward motion in the polar middle and upper mesosphere. These circulation changes lead to warming in the polar lower mesosphere but cooling in the polar middle and upper mesosphere, together with the radiative effects by ozone loss. At around the solar minimum period with low geomagnetic activity, however, the cooling tends to 
occur in the polar lower mesosphere when the downward motion becomes weak, which then reduces the 9-year mean temperature changes by only up to $\sim 1 \mathrm{~K}$ as shown in Figure 9 . In order to evaluate the adiabatic effects on the temperature changes by MEE-induced ozone loss, in particular, in association with geomagnetic activity, further investigation of specific changes of the meridional circulation associated with the MEE-induced ozone loss will be required.
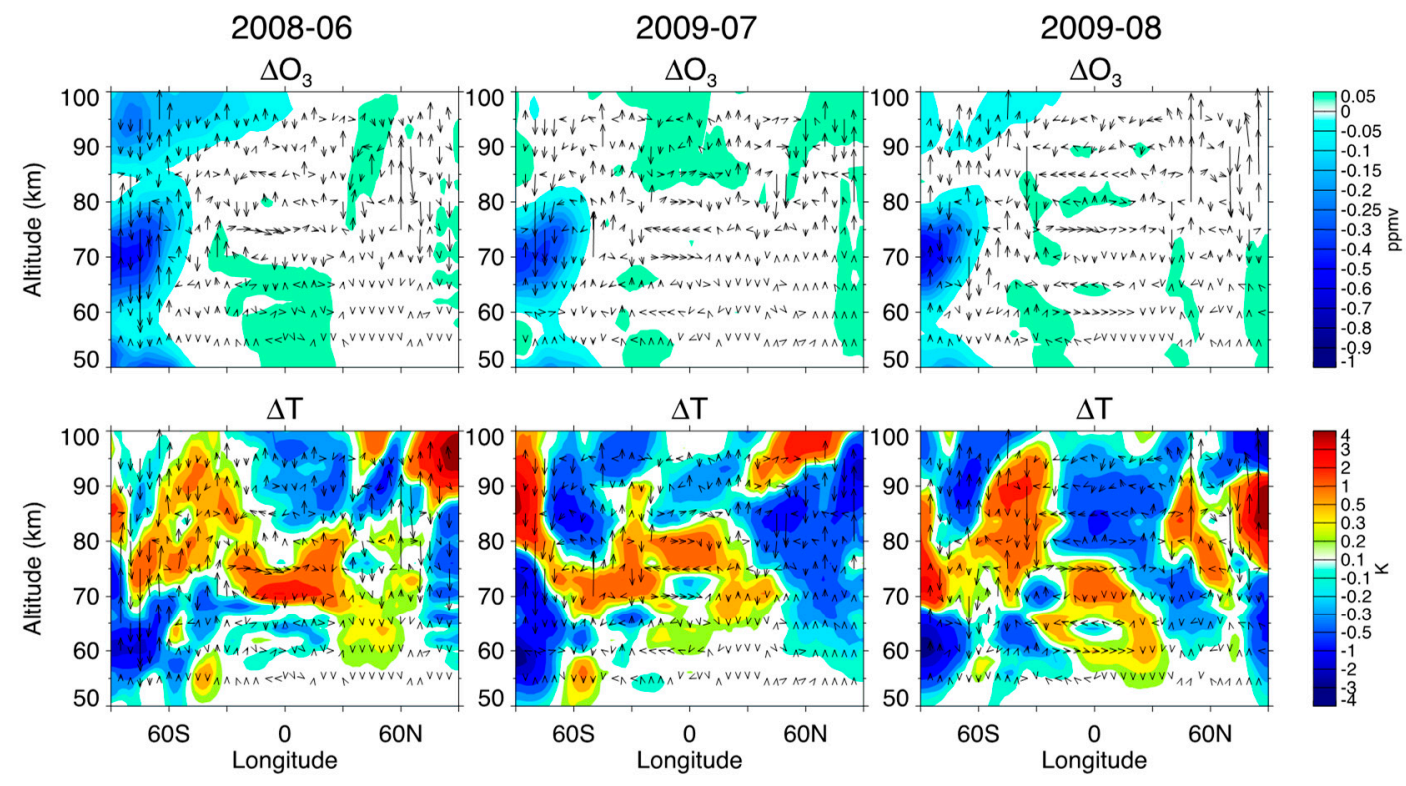

Velocity vector $\longleftarrow 1 \mathrm{~m} / \mathrm{s}$

Figure 11. Latitudinal variations of the differences (MEE-Control) of the monthly zonal mean ozone (top panels) and temperature (bottom panels) in the altitude range of 50-100 km in June 2008, July 2009, and August 2009 (around low geomagnetic activity/solar minimum period). The differences of residual mean velocity vector $\left(\bar{v}^{*}, \bar{w}^{*}\right)$ are also displayed by arrows in the figure. For a better visualization, $\bar{w}^{*}$ was multiplied by 333 in the residual mean velocity vector.
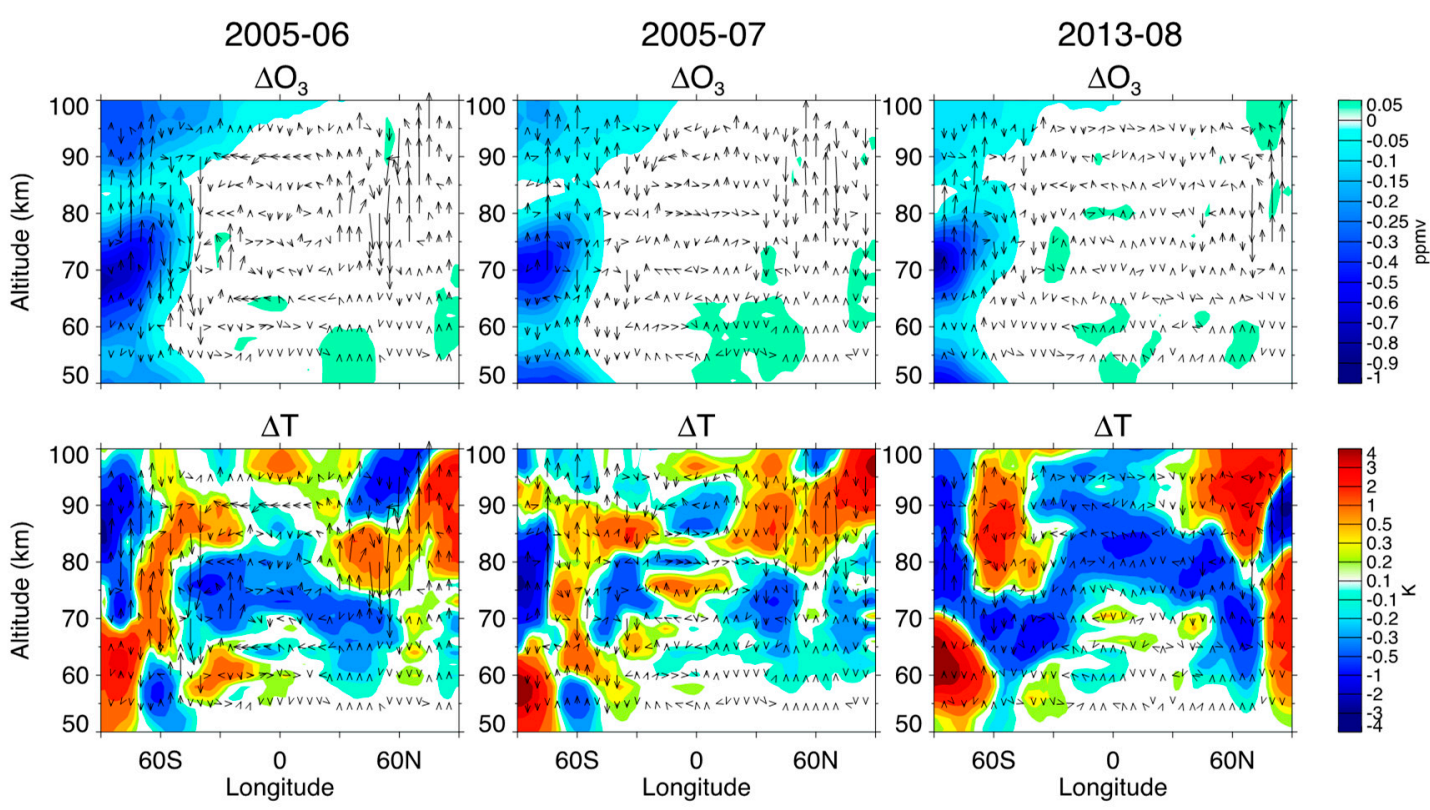

Velocity vector $\longleftarrow 1 \mathrm{~m} / \mathrm{s}$

Figure 12. Same as in Figure 11 but in June 2005, July 2005, and August 2013 (for high geomagnetic activity period). 


\section{Conclusions}

We investigated the chemical and dynamical effects driven by the MEE precipitation in the polar winter during the period of 2005-2013 by using SD-WACCM simulations. It was found that the MEE precipitation causes significant enhancements of $\mathrm{NO}_{x}$ and $\mathrm{HO}_{x}$ in the polar middle atmosphere and it reaches down to $30 \mathrm{~km}$ until late spring in the southern hemisphere, although the downward transport itself is reduced with MEE precipitation. The enhanced $\mathrm{NOx}$ and $\mathrm{HO}_{x}$ destroy ozone by up to $60 \%$ in the polar mesosphere, which leads to changes of the temperature and winds even in these specified dynamics simulations. The MEE-induced ozone loss generally reduces the radiative effects to decrease the temperature in the upper mesosphere, but increase the temperature in the lower mesosphere. There are also the meridional circulation changes to further change the mesospheric temperature by adiabatic effects. In particular, the meridional circulation changes during the low geomagnetic activity period seem to work to oppose the general temperature changes and average out to relatively small mean temperature changes for the 9-year period. In conclusion, the MEE precipitation produces large ozone loss in the winter polar mesosphere and results in significant temperature variabilities not only by radiative effects but also by adiabatic effects via meridional circulation changes in association with geomagnetic activity.

Author Contributions: Conceptualization, J.-H.L., G.J., Y.-S.K. and I.-S.S.; methodology, J.-H.L., G.J,, I.-S.S. and Y.-S.K.; formal analysis, J.-H.L. and G.J.; discussion, J.-H.L., G.J., Y.-S.K., H.H., A.S., E.T. and D.-Y.L.; data curation, J.-H.L. and G.J.; writing—original draft preparation, J.-H.L.; writing—review and editing, G.J.; visualization, J.-H.L.; supervision, G.J.; funding acquisition, G.J. All authors have read and agreed to the published version of the manuscript.

Funding: This research was funded by the grants PE21020 \& PE20360 from the Korea Polar Research Institute.

Institutional Review Board Statement: Not applicable.

Informed Consent Statement: Not applicable.

Data Availability Statement: GEOS5 data are provided by climate data gateway at NCAR (https: //www.earthsystemgrid.org/dataset/ucar.cgd.ccsm4.geos5.html).

Acknowledgments: Y.-S.K. is supported by basic research funding from Korea Astronomy and Space Science Institute (KASI). CESM source code is distributed through a public subversion repository ( http://www.cesm.ucar.edu/models/cesm1.0/).

Conflicts of Interest: The authors declare no conflict of interest.

\section{References}

1. Meraner, K.; Schmidt, H. Climate impact of idealized winter polar mesospheric and stratospheric ozone losses as caused by energetic particle precipitation. Atmos. Chem. Phys. 2018, 18, 1079-1089. [CrossRef]

2. Matthes, K.; Funke, B.; Andersson, M.E.; Barnard, L.; Beer, J.; Charbonneau, P.; Clilverd, M.A.; de Wit, T.D.; Haberreiter, M.; Hendry, A.; et al. Solar forcing for CMIP6 (v3.2). Geosci. Model Dev. 2017, 10, 2247-2302. [CrossRef]

3. Seppälä, A.; Matthes, K.; Randall, C.E.; Mironova, I.A. What is the solar influence on climate? Overview of activities during CAWSES-II. Prog. Earth Planet. Sci. 2014, 1, 24. [CrossRef]

4. Seppälä, A.; Clilverd, M.A. Energetic particle forcing of the Northern Hemisphere winter stratosphere: Comparison to solar irradiance forcing. Front. Phys. 2014, 2, RG4001. [CrossRef]

5. Rozanov, E.; Calisto, M.; Egorova, T.; Peter, T.; Schmutz, W. Influence of the precipitating energetic particles on atmospheric chemistry and climate. Surv. Geophys. 2012, 33, 483-501. [CrossRef]

6. Baumgaertner, A.J.G.; Seppala, A.; Jockel, P.; Clilverd, M.A. Geomagnetic activity related NOx enhancements and polar surface air temperature variability in a chemistry climate model: Modulation of the NAM index. Atmos. Chem. Phys. 2011, 11, 4521-4531. [CrossRef]

7. Jackman, C.H.; McPeters, R.D.; Labow, G.J.; Fleming, E.L.; Praderas, C.J.; Russell, J.M. Northern hemisphere atmospheric effects due to the July 2000 Solar Proton Event. Geophys. Res. Lett. 2001, 28, 2883-2886. [CrossRef]

8. Seppälä, A.; Verronen, P.T.; Sofieva, V.F.; Tamminen, J.; Kyrölä, E.; Rodger, C.J.; Clilverd, M.A. Destruction of the tertiary ozone maximum during a solar proton event. Geophys. Res. Lett. 2006, 33, 17. [CrossRef]

9. Porter, H.S.; Jackman, C.H.; Green, A.E.S. Efficiencies for production of atomic nitrogen and oxygen by relativistic proton impact in air. J. Chem. Phys. 1976, 65, 154-167. [CrossRef] 
10. Rusch, D.W.; Gérard, J.C.; Solomon, S.; Crutzen, P.J.; Reid, G.C. The effect of particle precipitation events on the neutral and ion chemistry of the middle atmosphere-I. Odd nitrogen. Planet. Space Sci. 1981, 29, 767-774. [CrossRef]

11. Sinnhuber, M.; Nieder, H.; Wieters, N. Energetic particle precipitation and the chemistry of the mesosphere/lower thermosphere. Surv. Geophys. 2012, 33, 1281-1334. [CrossRef]

12. Sinnhuber, M.; Wieters, N.; Winkler, H. The impact of energetic particle precipitation on the chemical composition of the middle atmosphere: Measurements and model predictions. In Climate and Weather of the Sun-Earth System (CAWSES): Highlights from a Priority Program; Lübken, F.-J., Ed.; Springer: Dordrecht, The Netherlands, 2013; pp. 275-299.

13. Nieder, H.; Winkler, H.; Marsh, D.R.; Sinnhuber, M. NOx production due to energetic particle precipitation in the MLT region: Results from ion chemistry model studies. J. Geophys. Res. Space 2014, 119, 2137-2148. [CrossRef]

14. Turunen, E.; Kero, A.; Verronen, P.T.; Miyoshi, Y.; Oyama, S.-I.; Saito, S. Mesospheric ozone destruction by high-energy electron precipitation associated with pulsating aurora. J. Geophys. Res. Atmos. 2016, 121. [CrossRef]

15. Andersson, M.E.; Verronen, P.T.; Marsh, D.R.; Seppälä, A.; Päivärinta, S.M.; Rodger, C.J.; Clilverd, M.A.; Kalakoski, N.; van de Kamp, M. Polar ozone response to energetic particle precipitation over decadal time scales: The role of medium-energy electrons J. Geophys. Res. Atmos. 2018, 123, 607-622. [CrossRef]

16. Funke, B.; Lopez-Puertas, M.; Fischer, H.; Stiller, G.P.; von Clarmann, T.; Wetzel, G.; Carli, B.; Belotti, C. Comment on “Origin of the January-April 2004 increase in stratospheric $\mathrm{NO}_{2}$ observed in northern polar latitudes" by Jean-Baptiste Renard et al. Geophys. Res. Lett. 2007, 34. [CrossRef]

17. Seppälä, A.; Verronen, P.T.; Clilverd, M.A.; Randall, C.E.; Tamminen, J.; Sofieva, V.; Backman, L.; Kyrölä, E. Arctic and Antarctic polar winter NO xand energetic particle precipitation in 2002-2006. Geophys. Res. Lett. 2007, 34, L19811. [CrossRef]

18. Randall, C.E.; Harvey, V.L.; Siskind, D.E.; France, J.; Bernath, P.F.; Boone, C.D.; Walker, K.A. NOx descent in the Arctic middle atmosphere in early 2009. Geophys. Res. Lett. 2009, 36. [CrossRef]

19. Sinnhuber, M.; Funke, B.; von Clarmann, T.; Lopez-Puertas, M.; Stiller, G.P.; Seppala, A. Variability of NOx in the polar middle atmosphere from October 2003 to March 2004: Vertical transport vs. local production by energetic particles. Atmos. Chem. Phys. 2014, 14, 7681-7692. [CrossRef]

20. Damiani, A.; Funke, B.; López-Puertas, M.; Santee, M.L.; Cordero, R.R.; Watanabe, S. Energetic particle precipitation: A major driver of the ozone budget in the Antarctic upper stratosphere. Geophys. Res. Lett. 2016, 43, 3554-3562. [CrossRef]

21. Lee, J.-H.; Jee, G.; Kwak, Y.-S.; Hong, S.-B.; Hwang, H.; Song, I.-S.; Lee, Y.-S.; Turunen, E.; Lee, D.-Y. Responses of nitrogen oxide to high-speed solar wind stream in the polar middle atmosphere. J. Geophys. Res. Space 2018, 123, 9788-9801. [CrossRef]

22. Andersson, M.E.; Verronen, P.T.; Rodger, C.J.; Clilverd, M.A.; Seppälä, A. Missing driver in the Sun-Earth connection from energetic electron precipitation impacts mesospheric ozone. Nat. Commun. 2014, 5, 5197. [CrossRef] [PubMed]

23. Randall, C.E.; Harvey, V.L.; Holt, L.A.; Marsh, D.R.; Kinnison, D.; Funke, B.; Bernath, P.F. Simulation of energetic particle precipitation effects during the 2003-2004 Arctic winter. J. Geophys. Res. Space 2015, 120, 5035-5048. [CrossRef]

24. Funke, B.; Ball, W.; Bender, S.; Gardini, A.; Harvey, V.L.; Lambert, A.; Lopez-Puertas, M.; Marsh, D.R.; Meraner, K.; Nieder, H.; et al. HEPPA-II model-Measurement intercomparison project: EPP indirect effects during the dynamically perturbed $\mathrm{NH}$ winter 2008-2009. Atmos. Chem. Phys. 2017, 17, 3573-3604. [CrossRef]

25. Smith, A.K.; Garcia, R.R.; Marsh, D.R.; Richter, J.H. WACCM simulations of the mean circulation and trace species transport in the winter mesosphere. J. Geophys. Res. 2011, 116, 2031. [CrossRef]

26. Päivärinta, S.M.; Verronen, P.T.; Funke, B.; Gardini, A.; Seppälä, A.; Andersson, M.E. Transport versus energetic particle precipitation: Northern polar stratospheric NOx and ozone in January-March 2012. J. Geophys. Res. Atmos. 2016, 121, 6085-6100. [CrossRef]

27. Hendrickx, K.; Megner, L.; Marsh, D.R.; Smith-Johnsen, C. Production and transport mechanisms of NO in the polar upper mesosphere and lower thermosphere in observations and models. Atmos. Chem. Phys. 2018, 18, 9075-9089. [CrossRef]

28. Arsenovic, P.; Rozanov, E.; Stenke, A.; Funke, B.; Wissing, J.M.; Mursula, K.; Tummon, F.; Peter, T. The influence of middle range energy electrons on atmospheric chemistry and regional climate. J. Atmos. Sol. Terr. Phys. 2016, 149, 180-190. [CrossRef]

29. Smith-Johnsen, C.; Marsh, D.R.; Orsolini, Y.; Tyssøy, H.N.; Hendrickx, K.; Sandanger, M.I.; Ødegaard, L.-K.G.; Stordal, F. Nitric oxide response to the April 2010 electron precipitation event: Using WACCM and WACCM-D with and without medium-energy electrons. J. Geophys. Res. Space 2018, 123, 5232-5245. [CrossRef]

30. Orsolini, Y.J.; Smith-Johnsen, C.; Marsh, D.R.; Stordal, F.; Rodger, C.J.; Verronen, P.T.; Clilverd, M.A. Mesospheric nitric acid enhancements during energetic electron precipitation events simulated by WACCM-D. J. Geophys. Res. Atmos. 2018, 123, 6984-6998. [CrossRef]

31. Newnham, D.A.; Clilverd, M.A.; Rodger, C.J.; Hendrickx, K.; Megner, L.; Kavanagh, A.J.; Seppälä, A.; Verronen, P.T.; Andersson, M.E.; Marsh, D.R.; et al. Observations and modeling of increased nitric oxide in the antarctic polar middle atmosphere associated with geomagnetic storm-driven energetic electron precipitation. J. Geophys. Res. Space 2018, 123, 6009-6025. [CrossRef]

32. Kinnison, D.E.; Brasseur, G.P.; Walters, S.; Garcia, R.R.; Marsh, D.R.; Sassi, F.; Harvey, V.L.; Randall, C.E.; Emmons, L.; Lamarque, J.F.; et al. Sensitivity of chemical tracers to meteorological parameters in the MOZART-3 chemical transport model. J. Geophys. Res. Atmos. 2007, 112. [CrossRef]

33. Marsh, D.R.; Garcia, R.R.; Kinnison, D.E.; Boville, B.A.; Sassi, F.; Solomon, S.C.; Matthes, K. Modeling the whole atmosphere response to solar cycle changes in radiative and geomagnetic forcing. J. Geophys. Res. Atmos. 2007, 112. [CrossRef] 
34. Jackman, C.H.; DeLand, M.T.; Labow, G.J.; Fleming, E.L.; Weisenstein, D.K.; Ko, M.K.W.; Sinnhuber, M.; Russell, J.M. Neutral atmospheric influences of the solar proton events in October-November 2003. J. Geophys. Res. Space 2005, 110. [CrossRef]

35. Solomon, S.; Rusch, D.W.; Gérard, J.C.; Reid, G.C.; Crutzen, P.J. The effect of particle precipitation events on the neutral and ion chemistry of the middle atmosphere: II. Odd hydrogen. Planet. Space Sci. 1981, 29, 885-893. [CrossRef]

36. Van de Kamp, M.; Seppälä, A.; Clilverd, M.A.; Rodger, C.J.; Verronen, P.T.; Whittaker, I.C. A model providing long-term data sets of energetic electron precipitation during geomagnetic storms. J. Geophys. Res. Atmos. 2016, 121. [CrossRef]

37. Tyssøy, H.N.; Sandanger, M.I.; Ødegaard, L.-K.G.; Stadsnes, J.; Aasnes, A.; Zawedde, A.E. Energetic electron precipitation into the middle atmosphere-Constructing the loss cone fluxes from MEPED POES. J. Geophys. Res. Space Phys. 2016, 121, 5693-5707. [CrossRef]

38. Fang, X.; Randall, C.E.; Lummerzheim, D.; Wang, W.; Lu, G.; Solomon, S.C.; Frahm, R.A. Parameterization of monoenergetic electron impact ionization. Geophys. Res. Lett. 2010, 37. [CrossRef]

39. Brakebusch, M.; Randall, C.E.; Kinnison, D.E.; Tilmes, S.; Santee, M.L.; Manney, G.L. Evaluation of whole atmosphere community climate model simulations of ozone during Arctic winter 2004-2005. J. Geophys. Res. Atmos. 2013, 118, 2673-2688. [CrossRef]

40. Frederick, J.E.; Orsini, N. The distribution and variability of mesospheric odd nitrogen: A theoretical investigation. J. Atmos. Terr. Phys. 1982, 44, 479-488. [CrossRef]

41. Solomon, S.; Crutzen, P.J.; Roble, R.G. Photochemical coupling between the thermosphere and the lower atmosphere: 1 . Odd nitrogen from 50 to $120 \mathrm{~km}$. J. Geophys. Res. 1982, 87, 7206-7220. [CrossRef]

42. Kvissel, O.-K.; Orsolini, Y.J.; Stordal, F.; Limpasuvan, V.; Richter, J.; Marsh, D.R. Mesospheric intrusion and anomalous chemistry during and after a major stratospheric sudden warming. J. Atmos. Sol. Terr. Phys. 2012, 78-79, 116-124. [CrossRef]

43. Lopez-Puertas, M.; Taylor, F.W. Non-LTE Radiative Transfer in the Atmosphere; World Scientific Publishing Co.: Singapore, 2001.

44. Kiehl, J.T.; Solomon, S. On the radiative balance of the stratosphere. J. Atmos. Sci. 1986, 43, 1525-1534. [CrossRef]

45. Mlynczak, M.G.; Mertens, C.J.; Garcia, R.R.; Portmann, R.W. A detailed evaluation of the stratospheric heat budget: 2. Global radiation balance and diabatic circulations. J. Geophys. Res. Atmos. 1999, 104, 6039-6066. [CrossRef]

46. Mertens, C.J.; Mlynczak, M.G.; Garcia, R.R.; Portmann, R.W. A detailed evaluation of the stratospheric heat budget: 1. Radiation transfer. J. Geophys. Res. Atmos. 1999, 104, 6021-6038. [CrossRef]

47. Körnich, H.; Becker, E. A simple model for the interhemispheric coupling of the middle atmosphere circulation. Adv. Space Res. 2010, 45, 661-668. [CrossRef]

48. Marsh, D.R. Chemical—Dynamical coupling in the mesosphere and lower thermosphere. In Aeronomy of the Earth's Atmosphere and Ionosphere; Abdu, M.A., Pancheva, D., Eds.; Springer: Dordrecht, The Netherlands, 2011; pp. 3-17.

49. Andrews, D.G.; Holton, J.R. Middle Atmosphere Dynamics; International Geophysics Series; Academic Press: Cambridge, MA, USA, 1987; Volume 40, p. 489.

50. Seppälä, A.; Lu, H.; Clilverd, M.A.; Rodger, C.J. Geomagnetic activity signatures in wintertime stratosphere wind, temperature, and wave response. J. Geophys. Res. Atmos. 2013, 118, 2169-2183. [CrossRef] 